\title{
Preliminary Evaluation of Gunshot Residue (GSR) Using 3-Aminophenol as a Substitute in Modified Griess Test
}

\author{
Siti Nurhazlin Jaluddin ${ }^{{ }^{*}}$, Zainiharyati Mohd Zain ${ }^{1}$, Mohamed Izzharif Abdul Halim ${ }^{1}$, Muhd Fauzi \\ Safian$^{1}$, Mohd Azri Abdul Rani ${ }^{1}$, and Mohamed Sazif Mohamed Subri ${ }^{2}$
}

${ }^{1}$ Faculty of Applied Sciences, Universiti Teknologi MARA, 40450 Shah Alam, Selangor, Malaysia

${ }^{2}$ Forensic Laboratory Royal Malaysia Police, 43200, Cheras, Selangor, Malaysia

\section{*Corresponding author: \\ email: hazlinjaluddin@gmail.com}

Received: August 6, 2021

Accepted: October 26, 2021

DOI: $10.22146 /$ ijc. 68265

\begin{abstract}
In forensic ballistics, gunshot residue (GSR) particles can be detected using screening or presumptive tests which are mainly focused on the chromophoric reaction. Most tests serve as an initial indication for a forensic investigator at the crime scene before instrumental analysis for definitive identification. The screening methods are known to be convenient, have fast analysis, and minimal preparation. In GSR analysis, the wellknown method of detecting GSR known as the Modified Griess Test (MGT) requires acid and heat for the reaction. Therefore, this study demonstrated a new and rapid screening test named the Rapid Griess Test (RGT) for the detection of GSR. This study intends to improve the functionality of previous screening reagents in determining nitrite $\left(\mathrm{NO}_{2}^{-}\right)$, the composition present after shooting activity. To do this, chemical reagents with an amino group, 3-aminophenol, were substituted with alpha-naphthol. The experiment showed that the reactions were positive color changes using standard $\mathrm{NO}_{2}{ }^{-}$and real GSR samples. The diazotization reactions involving sulfanilic acid and 3-aminophenol produced azo dyes that changed the solution from colorless to orange in the presence of $\mathrm{NO}_{2}{ }^{-}$. The RGT reagent will make it possible to avoid using heat and the addition of acetic acids in a sample to form chromophoric reactions. Moreover, the colorimetric method using Video Spectral Comparator (VSC) showed that RGT had higher intensity of the orange color when compared to MGT.
\end{abstract}

Keywords: gunshot residue (GSR); colorimetric method; screening test; nitrite $\left(\mathrm{NO}_{2}^{-}\right)$ detection; Modified Griess Test

\section{INTRODUCTION}

GSR evidence has become a substantial help in certain investigations by providing clues of the individuals who fired a gun. It has been used to estimate firing distances, identify bullet holes, differentiate entry and exit wounds, establish the kind of ammunition used, trace the trajectory of a projectile, and determine whether or not a person has discharged a firearm [1-4]. Generally, only trace amounts of GSR are deposited on the back of the hand, face, hair, and clothing of the shooter, and this material can be used to determine if the person has discharged a weapon. The analysis of GSR is essential evidence in forensics, and there is a need to develop a more sensitive and selective technique that performs more conclusive results for a more significant number of cases [5].

In recent years, the focus in forensic investigation has shifted towards portable and fast methods that can be performed in-situ rather than in an analytical laboratory [6-7]. Unfortunately, the current technique for detecting GSR cannot provide fast detection at a crime scene [8]. The screening method is an essential technique in forensic analysis that can minimize the time taken to analyze data. This technique can be achieved if the screening and confirmatory methods can be done at the crime scene. Most forensic analysts apply the use of color changes in order to determine the presence of nitro groups or heavy metals in GSR 
particles [9-10]. Griess [11] invented a novel screening method for detecting $\mathrm{NO}_{2}^{-}$in gunshot residues in 1858 . This method, also known as The Griess test, is used to detect the presence of $\mathrm{NO}_{2}{ }^{-}$by the combustion product of smokeless gun powder.

Nowadays, the Modified Griess Test (MGT) has been used to replace the original Griess test. The MGT has avoided the use of the toxic chemical 1naphthylethylenediamine dihydrochloride that was used in the original Griess test. The modified method is safer and uses a less expensive reagent than the original Griess test. However, the Griess test and MGT give several disadvantages to forensic analysis, namely requiring heat for the reaction to occur. Besides that, color tests show drawbacks like non-specificity to GSR and the requirement of proper storage and disposal of hazardous chemicals [12-14]. The significance of this study is to improve the functionality of previous screening reagents in the determination of $\mathrm{NO}_{2}{ }^{-}$composition that is present after shooting activity. For this reason, a slight modification of MGT has been made.

The new Rapid Griess Test (RGT) reagent was used to detect the presence of $\mathrm{NO}_{2}{ }^{-}$ions. This compound is mainly found after shooting due to the oxidation of nitrate (detected compound before shooting). In this study, a slight modification on the established Griess Test was done. RGT reagent was prepared with the substitution of alphanaphthol, the main reagent in MGT, to 3-aminophenol. This reagent substitution is necessary to avoid the use of heat and the addition of nitric acid in conventional methods. Besides that, the selected chemical reagent is less toxic and less expensive compared to alpha-naphthol.

This study also reported the usage of Video Spectral Comparator (VSC) as a colorimetric analysis in the determination of $\mathrm{NO}_{2}^{-}$in the GSR sample. Previous research proved that this rapid and non-destructive method had successfully revealed the GSR pattern on clothing, including dark and bloodstained clothing [15-16].

This spectrum intensity can be accurately measured by the value of CIELAB or L* $a^{*} b^{*}$. In 1931, Commission Internationale de I'Eclairage (CIE) established a colorimetric method to quantify and physically describe human color perception [17]. The colorimetric method is widely used in industries to define a standard for the quality control of products [18]. The colorimetric method has a function as color coordination in the color space. Brightness and chromaticity are two important factors in determining the colorimetric spectrum. Brightness is symbolized as $\mathrm{L}^{*}$ (Lightness, luminosity, or luminance) and has a range from ' 0 ' (dark/black) to ' 100 ' (light/white) [19]. The intensity is measured as follows; high concentrated solutions have low numbers (0-50) and low concentrated solutions have high numbers (51100). The chromaticity spectrum is based on three primary colors of blue, green, and red [20]. The $\mathrm{a}^{\star}$ scale value indicates the degree of redness with a positive $(+)$ number and greenness with a negative (-) number.

Meanwhile, the $\mathrm{b}^{*}$ scale measures the yellow and blue colors, where positive numbers represent yellowness, and negative numbers represent blueness. Indeed, all visible colors are present by mixing these colors in different quantities. Meanwhile, the central point on the colorimetric spectrum shows the white color spot. This central area represents an equal mixture of the primary colors [21].

\section{- EXPERIMENTAL SECTION}

\section{Materials}

All reagents and chemicals used in these experiments were of analytical grade. Alpha naphthol and the chemicals used for the preparation of the RGT reagent that include 3-Aminophenol $\left(\mathrm{C}_{6} \mathrm{H}_{4}\left(\mathrm{NH}_{2}\right) \mathrm{OH}, \geq\right.$ 99\%) and Sulfanilic Acid $\left(\mathrm{C}_{6} \mathrm{H}_{7} \mathrm{NO}_{3} \mathrm{~S}, \geq 99 \%\right)$, were purchased from Sigma Aldrich. Methanol $(\mathrm{MeOH}, \geq$ 99\%) purchased from Merck was used without further purification.

\section{Procedure}

\section{Preparation of the Rapid Griess Test (RGT) reagent}

The method for the MGT reagent preparation in this study followed the steps of a previous study [16]. Furthermore, the RGT reagent was prepared by substitution of alpha naphthol in MGT with 3aminophenol. Then, $28 \mathrm{~g}$ of 3-aminophenol in $100 \mathrm{~mL}$ of methanol was added into $5 \mathrm{~g}$ of sulfanilic acid solution. The solution was stored in a sealed amber bottle. 


\section{Preparation of the standard nitrite $\left(\mathrm{NO}_{2}^{-}\right)$solution}

The screening test method was performed using standard $\mathrm{NO}_{2}{ }^{-}$solutions with different concentrations: $250,200,150,100$, and $50 \mathrm{ppm}$. This step was conducted to identify the concentration of $\mathrm{NO}_{2}^{-}$that can react with the RGT reagent. Meanwhile, the samples of GSR collected on the target materials were tested directly at the shooting location.

\section{Collection of GSR samples}

In order to investigate the effectiveness of the RGT reagent on GSR samples, a shooting test was performed using a Colt (F1) revolver and Smith \& Wesson Special $+\mathrm{P}$ (F2) revolver, Sig Sauer P226 (F3) pistol, and Walther P99 (F4) pistol. The ammunition used was from Syarikat Malaysia Explosive (SME), 0.38 inch and $9 \mathrm{~mm}$. GSR was directly collected from the target materials before it was tested using the RGT reagent. A shooter conducted the shooting test on duty from the Royal Malaysian Police. This shooting and screening test for detecting $\mathrm{NO}_{2}^{-}$in GSR was done in the Forensic Laboratory of the Royal Malaysia Police (RMP) Cheras, Kuala Lumpur. Next, to confirm the presence of $\mathrm{NO}_{2}{ }^{-}$in GSR, the sample was analyzed using Video Spectral Comparator (VSC).

\section{- RESULTS AND DISCUSSION}

\section{Color Changes of Standard Nitrite $\left(\mathrm{NO}_{2}{ }^{-}\right)$}

According to Dalby and co-workers [12], the inexpensive, simple, and rapid color test has become an attractive method even though the results are only for screening purposes. However, very few studies on chemical color tests can be used for screening purposes during forensic investigation [22]. Furthermore, conventional chemical color tests are troublesome as some require heat and bulk analysis techniques with a lack of specificity. For instance, the established Griess test method for the detection of $\mathrm{NO}_{2}^{-}$in GSR is contributing contamination as the result of heat from the iron [23]. Therefore, this research would address these difficulties by providing an in-situ, reliable and valid method for analyzing GSR samples. Furthermore, the effectiveness of the reagent can be achieved by modifying the substance used in a chemical color test so that it can provide a color change in situ for screening purposes.

The presence of $\mathrm{NO}_{2}^{-}$residue will cause the formation of an orange color as a result of the chromophoric reaction. This reaction occurs due to the formation of Azo-dyes. The reaction known as the diazotization reaction occurs when nitrosating agent reacts with sulfanilic acid to produce a diazonium ion [24-25]. The nitrosating agents are derived from the acid-catalyzed formation of nitrous acid from $\mathrm{NO}_{2}^{-}$. In this case, $\mathrm{NO}_{2}{ }^{-}$was obtained from the GSR. Next, the diazonium ion will react with aminophenol to form an azo dye (orange color solution). Fig. 1 shows the schematic reactions of $\mathrm{NO}_{2}{ }^{-}$and aminophenol to form an azo dye.

Ideally, $\mathrm{NO}_{2}{ }^{-}$reacts with 3-aminophenol to form an orange-yellow color solution. The concentrations of an element in a solution can be determined using colorimetric analysis. Colorimetric analysis can be defined as a technique in determining the concentration of chemical compounds such as organic or inorganic compounds in a solution with a color reagent. In this study, a video spectral comparator was used to measure the colorimetrics of the reagent solution that was used to react with the samples. Fig. 2 shows the color changes with the different concentrations of $\mathrm{NO}_{2}{ }^{-}$solution that are visible to the human eye.

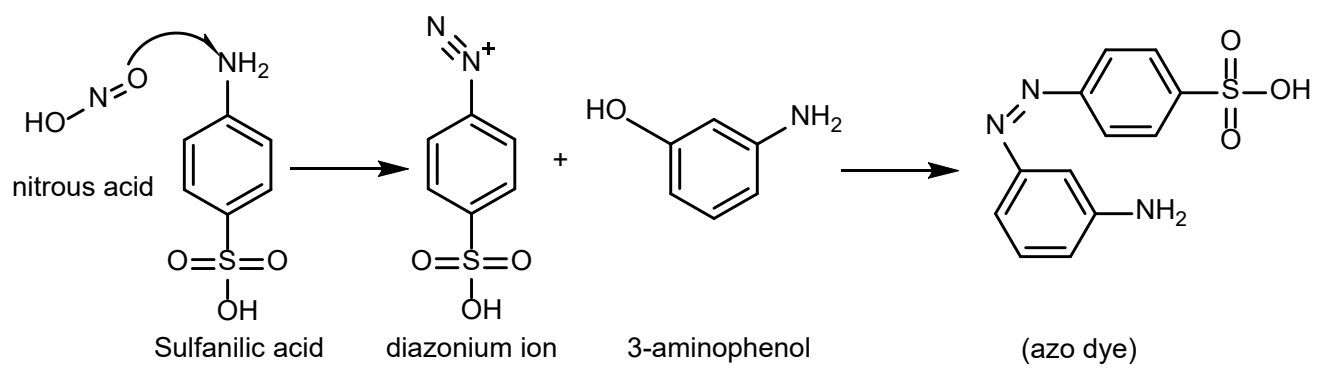

Fig 1. Schematic reactions of nitrite $\left(\mathrm{NO}_{2}^{-}\right)$and 3-aminophenol. 


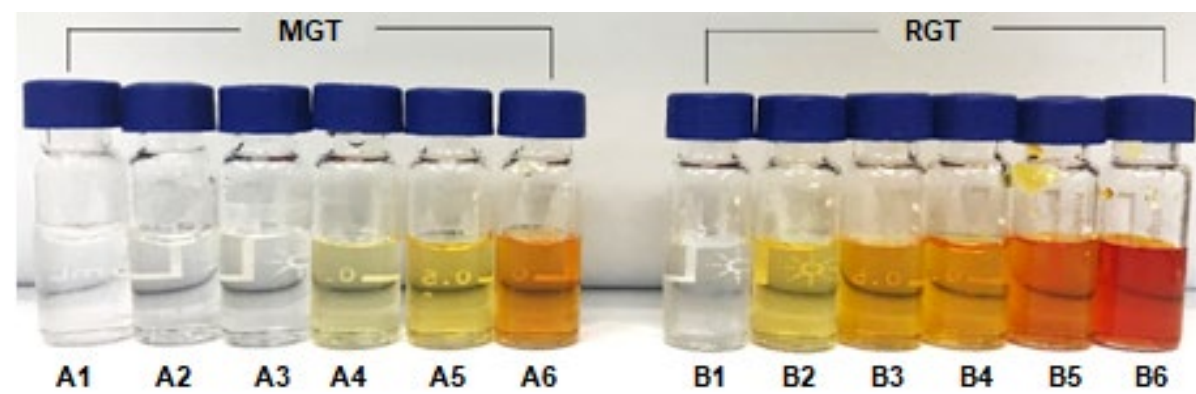

Fig 2. Vials contain (A1) MGT blank, with (A2) 50 ppm, (A3) 100 ppm, (A4) 150 ppm, (A5) 200 ppm, and (A6) 250 ppm of $\mathrm{NO}_{2}{ }^{-}$solution, while vial (B1) contain RGT blank, with (B2) 50 ppm, (B3) 100 ppm, (B4) 150 ppm, (B5) 200 ppm, and (B6) 250 ppm of $\mathrm{NO}_{2}^{-}$solution

Fig. 2 shows the color changes of the solution from colorless (blank) to different tones of yellow and orange. No color formation occurred in vials A2 and A 3 because the concentration of the $\mathrm{NO}_{2}{ }^{-}$solutions were too low to react to the MGT. Thus, the earliest change due to the reaction of the MGT reagent and the $\mathrm{NO}_{2}{ }^{-}$solution occurred in vial A4. The reaction between MGT and 150 ppm of standard $\mathrm{NO}_{2}^{-}$resulted in a yellowish color solution. Meanwhile, vials A5 and A6 show the formation of a yellow and orange color solution, respectively. Unlike the RGT reagent, acetic acid needs to be added to the MGT solution. This solution also required heating for the reaction to occur. In the meantime, the reaction of the standard $\mathrm{NO}_{2}{ }^{-}$solution and RGT had occurred in all vials. Vial B5 and B6 showed the darkest color solutions. This detection will help in the determination of particle compounds in crime scenes. Furthermore, the reactions between the RGT reagent and the standard $\mathrm{NO}_{2}{ }^{-}$solution showed color changes without adding acetic acid or heating process. Fig. 3 shows the colorimetric spectrum of the blank and test reagent with $\mathrm{NO}_{2}{ }^{-}$solution. Both the blank solution in vial $\mathrm{A} 1$ and $\mathrm{B} 1$ marked the white color spectrum with the values $\left(\mathrm{L}^{*}=82.6, \mathrm{a}^{*}=1.7, \mathrm{~b}^{*}=2.8\right)$ and $\left(\mathrm{L}^{\star}=87.5, \mathrm{a}^{\star}=1.2, \mathrm{~b}^{\star}=3.4\right)$ respectively.

MGT with $50 \mathrm{ppm}$ and $100 \mathrm{ppm}$ of $\mathrm{NO}_{2}^{-}$solution in vial A2 $\left(\mathrm{L}^{*}=82.5, \mathrm{a}^{*}=0.7, \mathrm{~b}^{*}=11.4\right)$, and A3 $\left(\mathrm{L}^{*}=82.5\right.$, $\left.\mathrm{a}^{\star}=0.9, \mathrm{~b}^{\star}=14.4\right)$ respectively showed unchanged color solutions. The reaction of the MGT reagent towards the $\mathrm{NO}_{2}{ }^{-}$solution in vial $\mathrm{A} 4\left(\mathrm{~L}^{*}=78.9, \mathrm{a}^{*}=3.6, \mathrm{~b}^{*}=14.8\right)$ showed a yellowish color solution. Meanwhile, the spectrum shows that $\mathrm{A} 5\left(\mathrm{~L}^{*}=73.3, \mathrm{a}^{*}=-1.7, \mathrm{~b}^{*}=17.1\right)$ was plotted near B2 $\left(\mathrm{L}^{*}=77.5, \mathrm{a}^{*}=1.3, \mathrm{~b}^{*}=17.6\right)$. Similar to

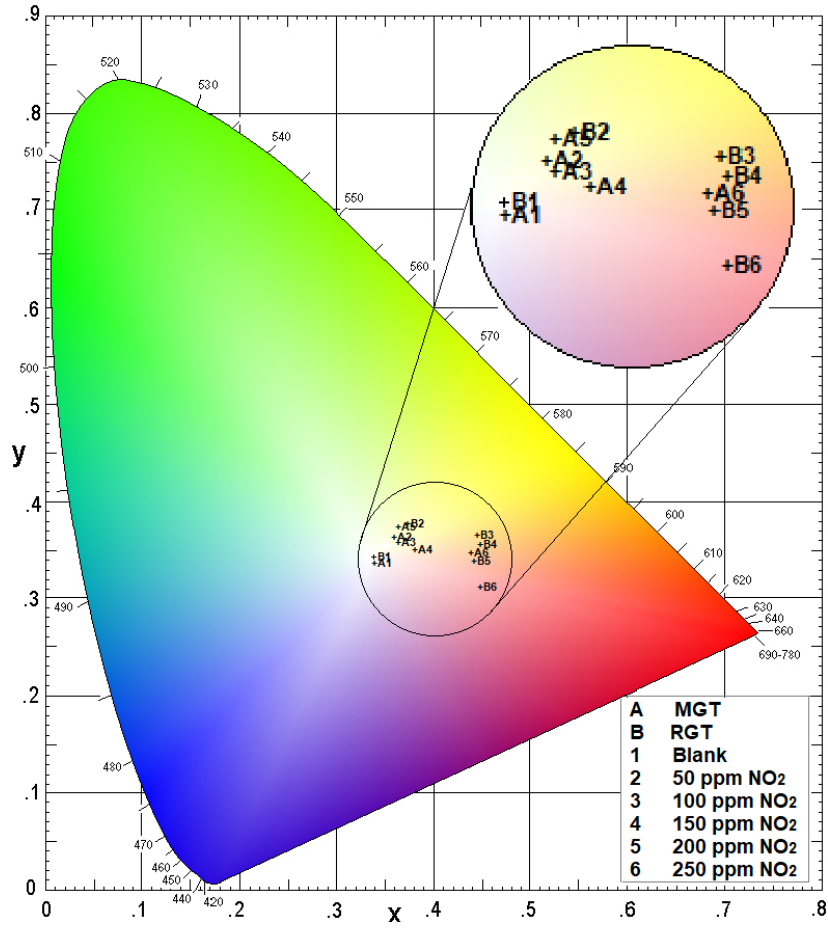

Fig 3. The colorimetric spectrum of (A) MGT and (B) RGT reagent with different concentrations of $\mathrm{NO}_{2}{ }^{-}$ solution

colorimetric spectrum detection, both A5 and B2 vials showed almost the same yellow color solutions. However, the negative value of $\mathrm{a}^{\star}$ for $\mathrm{A} 5$ indicates that the solution is near to the green color spectrum. While, vial A6 $\left(\mathrm{L}^{*}=\right.$ $\left.67.3, \mathrm{a}^{*}=29.9, \mathrm{~b}^{*}=22.1\right)$ showed an orange solution.

Meanwhile, the reactions of the RGT reagent and the standard $\mathrm{NO}_{2}{ }^{-}$solution in vial $\mathrm{B} 3\left(\mathrm{~L}^{*}=73.3, \mathrm{a}^{*}=\right.$ $\left.29.9, \mathrm{~b}^{*}=30.0\right)$, and $\mathrm{B} 4\left(\mathrm{~L}^{*}=71.7, \mathrm{a}^{\star}=32.5, \mathrm{~b}^{*}=27.4\right)$ showed bright orange solutions. The orange solution in vial B5 $\left(\mathrm{L}^{*}=64.3, \mathrm{a}^{*}=30.9, \mathrm{~b}^{*}=20.6\right)$ was formed when 
$200 \mathrm{ppm}$ of $\mathrm{NO}_{2}{ }^{-}$standard solution reacted with the RGT reagent. Vial B6 $\left(\mathrm{L}^{*}=62.2, \mathrm{a}^{\star}=44.6, \mathrm{~b}^{*}=12.7\right)$ which contained the RGT reagent and $250 \mathrm{ppm}$ of $\mathrm{NO}_{2}{ }^{-}$solution showed the formation of a dark orange solution after the reaction occurred.

Indeed, the reaction between the RGT reagent and the standard $\mathrm{NO}_{2}^{-}$solutions showed the different values of colorimetric data. The RGT reagent containing $250 \mathrm{ppm}$ of $\mathrm{NO}_{2}^{-}$(vial B6) showed a low number of $\mathrm{L}^{*}$, which indicated the dark color of the solution or the highest solution concentration. The color of the solution in vial B6 was significantly darker compared to MGT that reacted with $250 \mathrm{ppm}$ of $\mathrm{NO}_{2}^{-}$solution in vial A6. Moreover, the colorimetric measurements showed an increasing redness value, $\mathrm{a}^{*}$, when the concentration of the standard $\mathrm{NO}_{2}{ }^{-}$solutions that reacted with the RGT reagent increased. Therefore, it can be stated that the color tone of the solution becomes darker as the concentration increases. The color changes of the solution proved that RGT is more efficient compared to conventional MGT.

However, to determine the parameter and performance of the RGT reagent, the sensitivity tests were done in this study. Table 1 represents the absorbance versus concentration of $\mathrm{NO}_{2}^{-}$(ppm) in MGT and RGT that were measured by UV-VIS spectrometry at $354 \mathrm{~nm}$. Based on the signals obtained from the UV-VIS spectrometer, the calibration curves for MGT and RGT reagents were plotted for five different concentrations of $\mathrm{NO}_{2}{ }^{-}$and are presented in Fig. 4.

The linear regression data for the calibration curves showed a good linear relationship over the concentration range of $50 \mathrm{ppm}$ to $250 \mathrm{ppm}$ for nitrite. The linear regression equation for RGT was $\mathrm{Y}=0.0035 \mathrm{x}+0.0136$, where $\mathrm{R}^{2}=1$. Meanwhile, linear regression for MGT was $\mathrm{Y}=0.0019 \mathrm{x}+0.032$, where $\mathrm{R}^{2}=0.9864$. The sensitivity of the analyte towards the reagents can be verified using the limit of detection (LOD) and limit of quantification (LOQ). According to Shrivastava [26], LOD is the lowest analyte concentration that can be measured or detected by a given analytical procedure. Meanwhile, LOQ is the lowest concentration that can be quantitated reliably [27-28].

The LOD was determined as $3.3^{\star} S_{y / x} / b$, where $S_{y / x}$ is the residual standard deviation while $b$ is equal to the slope or sensitivity corresponding to the calibration curve [29]. Meanwhile, LOQ can be calculated using the formula $10^{\star} S_{y / x} / b$. In this study, the LOD and LOQ for the RGT reagent were found at $1.5 \mathrm{ppm}$ and $4.6 \mathrm{ppm}$, respectively. Meanwhile, the MGT reagent had a LOD value of 35.8 and a LOQ value of 108.6. Even though MGT reagents are the most frequently used method to determine nitrite, the method is not suitable for GSR determination. It is because MGT requires the addition of acid and heat for the reaction to occur. In conclusion,

Table 1. The data of absorbance and concentration from UV-VIS spectrometry.

\begin{tabular}{cccccc}
\hline \multicolumn{3}{c}{ MGT } & \multicolumn{4}{c}{ RGT } \\
\hline vials & $\begin{array}{c}\text { Conc. of } \\
\mathrm{NO}_{2}^{-}(\mathrm{ppm})\end{array}$ & Abs. & vials & $\begin{array}{c}\text { Conc. of } \\
\mathrm{NO}_{2}^{-}(\mathrm{ppm})\end{array}$ & Abs. \\
\hline A2 & 50 & 0.084 & $\mathrm{~B} 2$ & 50 & 0.186 \\
A3 & 100 & 0.137 & $\mathrm{~B} 3$ & 100 & 0.359 \\
A4 & 150 & 0.258 & $\mathrm{~B} 4$ & 150 & 0.534 \\
A5 & 200 & 0.341 & $\mathrm{~B} 5$ & 200 & 0.703 \\
A6 & 250 & 0.463 & $\mathrm{~B} 6$ & 250 & 0.878 \\
\hline
\end{tabular}

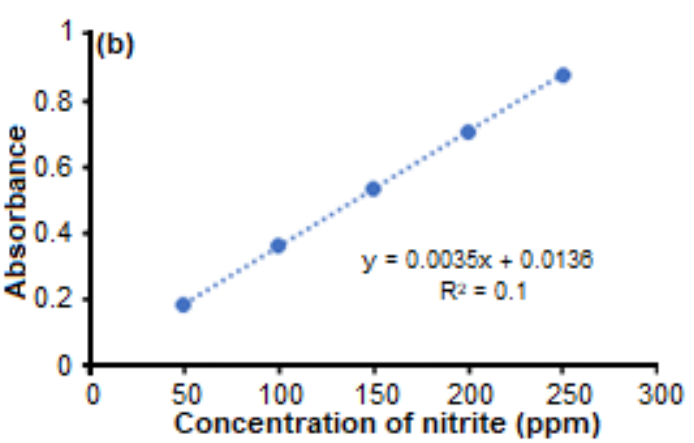

Fig 4. Calibration curve of (a) MGT and (b) RGT reagent using UV-VIS spectrometry 
the LOD and LOQ values confirmed the effectiveness of the RGT reagent compared to the MGT reagent in determining GSR. Therefore, this reagent has the potential to become a simple and fast screening test at the crime scene.

\section{Color Changes of the RGT Reagent on GSR Samples}

The effectiveness of the RGT reagent at a crime scene can be determined using the GSR samples. For this purpose, the shooting test was done at a closed, unventilated area using SME ammunition fired from four types of firearms, namely Colt revolver (F1), Smith \& Wesson special P revolver (F2), Sig Sauer P226 pistol (F3), and Walther $\mathrm{P} 99$ pistol (F4).

Fig. 5 shows the color changes of the RGT reagent when reacting with different amounts (mg) of GSR samples from the F1 and F2 revolver. The reaction between the RGT reagents and the GSR samples took place within $30 \mathrm{~min}$, forming color changes, as shown in Fig. 5. The observations showed different color ranges that is visible to the human eye. There are different colors of the solutions, which include the yellowish color, yellow, orange and dark orange. However, the color changes that are measured by human eyes might cause biased results. Therefore, the intensity of the color of the solutions was measured using a colorimetric test for more accurate results, as shown in Fig. 6.

Fig. 6 represents the colorimetric spectrum of the RGT reagent with the GSR samples, from the F1 and F2 revolver. Vial 1 that contained the blank reagent marked the white color spectrum with the value of $\left(\mathrm{L}^{*}=87.5, \mathrm{a}^{*}=\right.$ $1.2, \mathrm{~b}^{\star}=3.4$ ). Referring to the observation on Fig. 5 and the spectrum from Fig. 6, vial 2a that consisted of $5 \mathrm{mg}$
GSR from F1 showed a yellowish color $\left(L^{*}=77.1, \mathrm{a}^{\star}=\right.$ $\left.1.3, \mathrm{~b}^{*}=13.0\right)$, while $10 \mathrm{mg}$ of GSR in vial $2 \mathrm{~b}\left(\mathrm{~L}^{*}=73.1\right.$, $\left.\mathrm{a}^{\star}=2.5, \mathrm{~b}^{*}=32.4\right)$ formed a yellow solution when it reacted with the RGT reagent. Furthermore, both vial 2c and $2 \mathrm{~d}$ showed yellow colored solutions with the value of $\left(\mathrm{L}^{*}=73.1, \mathrm{a}^{*}=14, \mathrm{~b}^{*}=35.2\right)$, and $\left(\mathrm{L}^{*}=67.1, \mathrm{a}^{*}=\right.$ $\left.19.6, b^{*}=26.6\right)$, respectively. Vial $2 e$ that consisted of $25 \mathrm{mg}$ GSR from F1 showed a dark orange solution that remarked the color intensity at $\left(\mathrm{L}^{*}=60.5, \mathrm{a}^{*}=35.5, \mathrm{~b}^{*}\right.$ $=7.0$ ).

Meanwhile, the GSR from F2 in vial $3 a$ and $3 b$

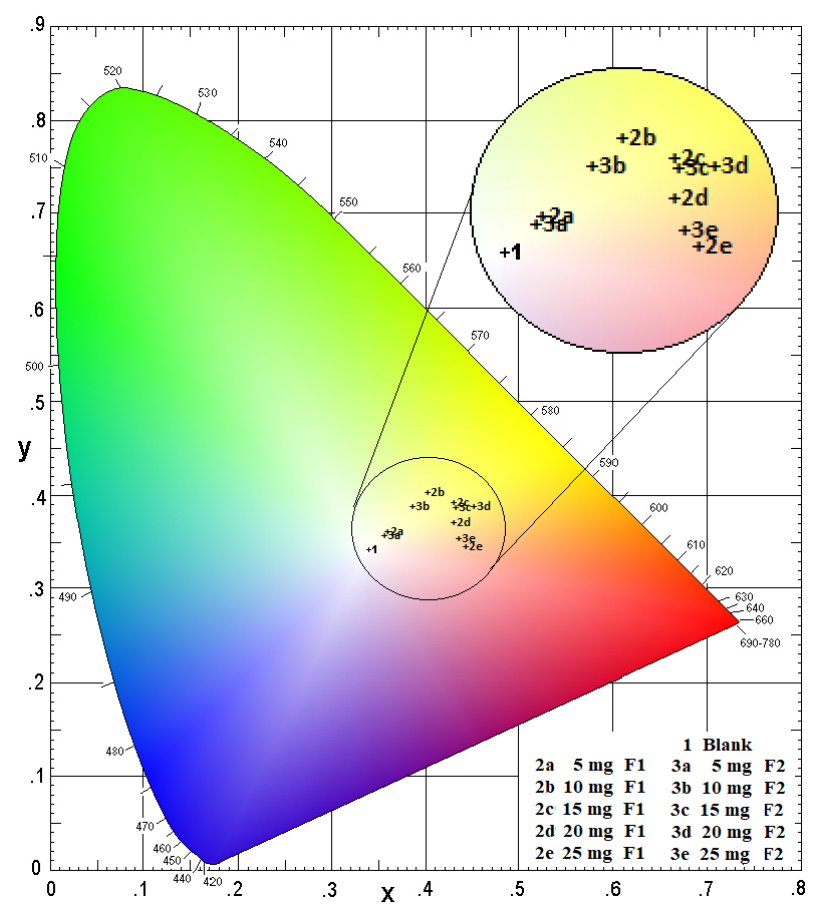

Fig 6. The colorimetric spectrum of the RGT reagent with different weights of GSR samples from the F1 and F2 revolver

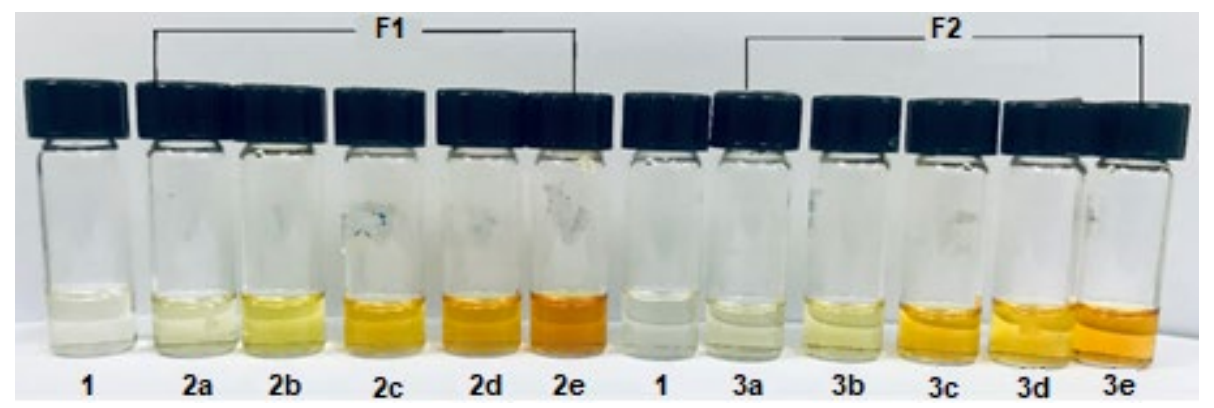

Fig 5. Color changes of the RGT reagent (1) Blank with GSR samples of (a) $5 \mathrm{mg}$, (b) $10 \mathrm{mg}$, (c) $15 \mathrm{mg}$, (d) $20 \mathrm{mg}$ and (e) $25 \mathrm{mg}$ from (2) F1 and (3) F2 revolver 
showed a yellowish solution with the value of intensity $\left(\mathrm{L}^{*}\right.$ $\left.=80.6, \mathrm{a}^{*}=0.2, \mathrm{~b}^{*}=11.7\right)$ and $\left(\mathrm{L}^{*}=75.2, \mathrm{a}^{*}=1.6, \mathrm{~b}^{*}=\right.$ 26.1) respectively. The minimum value of $a^{*}(0.2)$ for $3 a$ indicates that the solution was near to the white color spectrum. The orange solution in vial $3 \mathrm{c}$ and $3 \mathrm{~d}$ had intensity value of $\left(\mathrm{L}^{*}=74.0, \mathrm{a}^{*}=16.6, \mathrm{~b}^{*}=34.5\right)$ and $\left(\mathrm{L}^{*}\right.$ $\left.=74.9, \mathrm{a}^{*}=17.6, \mathrm{~b}^{*}=37.3\right)$ respectively. The solution in vial $3 \mathrm{e}$ with the intensity value of $\left(\mathrm{L}^{*}=62.2, \mathrm{a}^{*}=44.6, \mathrm{~b}^{*}\right.$ $=12.7$ ) showed a dark orange solution that is visible to the human eye. The $25 \mathrm{mg}$ GSR from F1 in vial 2e showed the highest redness value, $\mathrm{a}^{*}$, followed by $25 \mathrm{mg}$ of GSR from F2 in vial 3e. The high value of redness is caused by the dark colored solution from both samples. Moreover, the lowest $\mathrm{L}^{*}$ value in vials $2 \mathrm{e}$ and $3 \mathrm{e}$ also indicated a darker colored solution compared to the other samples. The different colors of the solutions indicates that the amount of GSR affected the formation of the color of the solutions.

Fig. 7 shows the color changes of the RGT reagent when reacting with different amounts (mg) of GSR samples from the F3 and F4 pistols, while Fig. 8 represents the colorimetric spectrum of the RGT reagent with different weights of GSR from the F3 and F4 pistols. Fig. 7 shows that the vials that consisted of GSR from F3 showed different color changes: a yellowish solution in vial $4 \mathrm{a}$, yellow solutions in vial $4 \mathrm{~b}$ and $4 \mathrm{c}$, an orange solution in vial $4 \mathrm{~d}$, and a dark orange solution in vial $4 \mathrm{e}$. Meanwhile, vials that consisted of GSR from F4 showed a yellowish solution in vial $5 \mathrm{a}$, a yellow solution in vial $5 \mathrm{~b}$, and a dark orange solution in vial $5 \mathrm{e}$, leaving the rest of the vials with orange colored solutions.

Fig. 8 shows that the blank solution, located on the white color spectrum, has the intensity value of $\left(\mathrm{L}^{*}=87.5\right.$, $\left.\mathrm{a}^{\star}=1.2, \mathrm{~b}^{*}=3.4\right)$. The colorimetric spectrum shows that
$4 \mathrm{a}\left(\mathrm{L}^{*}=81.6, \mathrm{a}^{*}=-0.4, \mathrm{~b}^{*}=16.1\right)$ and $5 \mathrm{a}\left(\mathrm{L}^{*}=77.8, \mathrm{a}^{*}=\right.$ $\left.1.9, \mathrm{~b}^{*}=12.9\right)$ were located near the white spectrum. The negative redness value, $\mathrm{a}^{*}=-0.4$ for $4 \mathrm{a}$ indicates that the solution is leaning toward the green spectrum. Similarly, when observed through the human eyes, the color of the solution of vials $4 \mathrm{a}$ and $5 \mathrm{a}$ was very close to white. However, the minimum changes from colorless to yellowish solution prove the effectiveness of the RGT reagent as a screening test reagent in determining GSR.

The yellow solution in vial $4 \mathrm{~b}\left(\mathrm{~L}^{*}=81.7, \mathrm{a}^{*}=0.2\right.$, $\left.\mathrm{b}^{*}=35.1\right)$ and $4 \mathrm{c}\left(\mathrm{L}^{*}=72.6, \mathrm{a}^{*}=9.5, \mathrm{~b}^{*}=35.1\right)$ showed the highest value of yellowness, $b^{*}$ in the colorimetric spectrum followed by $5 \mathrm{~b}\left(\mathrm{~L}^{*}=69.1, \mathrm{a}^{*}=10.1, \mathrm{~b}^{*}=29.0\right)$

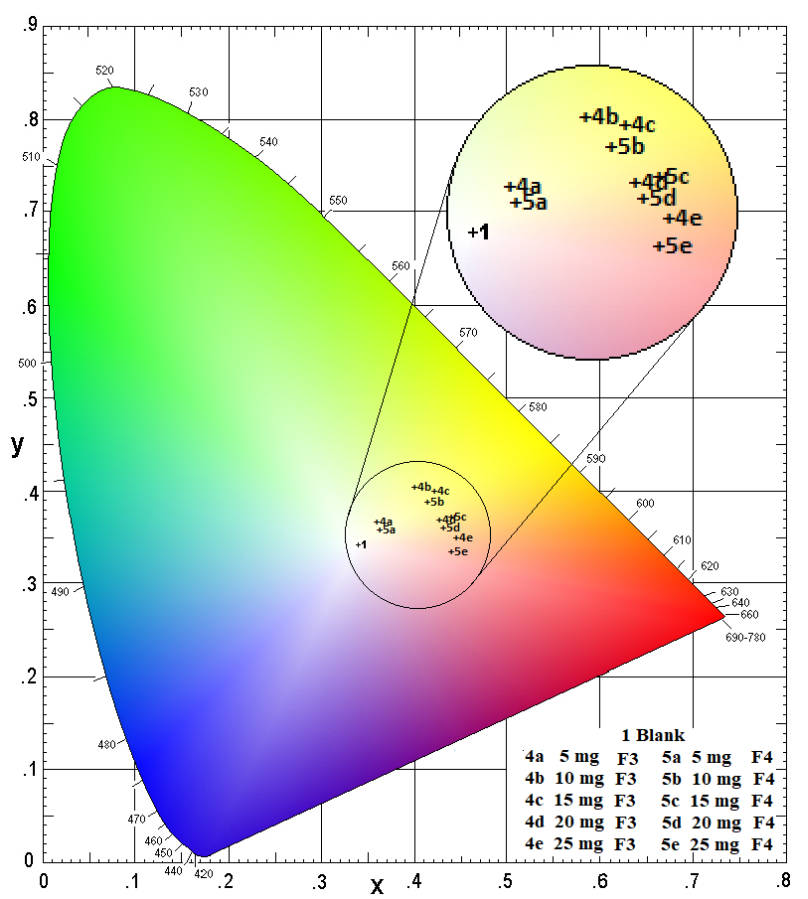

Fig 8. The colorimetric spectrum of RGT reagent with different weights of GSR samples from F3 and F4 pistols

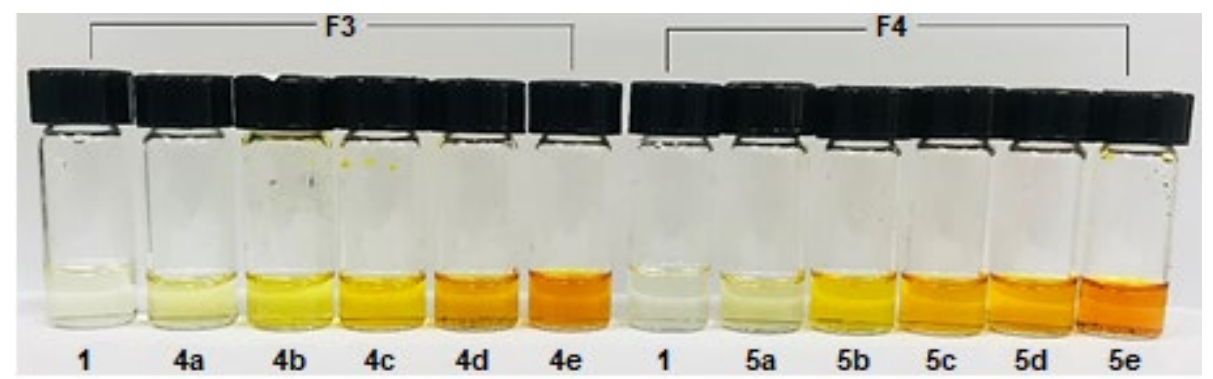

Fig 7. Color changes of RGT reagent (1) Blank with GSR samples of (a) $5 \mathrm{mg}$, (b) $10 \mathrm{mg}$, (c) $15 \mathrm{mg}$, (d) $20 \mathrm{mg}$ and (e) $25 \mathrm{mg}$ from (4) F3 and (5) F4 pistol 
which also formed a yellow solution. Meanwhile, the grouping of vial $4 \mathrm{~d}\left(\mathrm{~L}^{*}=68.1, \mathrm{a}^{*}=20.5, \mathrm{~b}^{*}=26.1\right), 5 \mathrm{c}\left(\mathrm{L}^{*}\right.$ $\left.=69.2, \mathrm{a}^{*}=23.3, \mathrm{~b}^{*}=29.7\right)$ and $5 \mathrm{~d}\left(\mathrm{~L}^{*}=66.2, \mathrm{a}^{*}=23.4\right.$, $\left.b^{*}=23.4\right)$ are due to the similar values of $L^{*}, a^{*}$, and $b^{*}$. The grouping of the samples showed the intensity of the color of the solution that were slightly similar to each other. In addition, both $25 \mathrm{mg}$ of GSR from F3 in vial 4e $\left(\mathrm{L}^{*}=63.7, \mathrm{a}^{*}=30.6, \mathrm{~b}^{*}=21.8\right)$ and $\mathrm{F} 4$ in vial $5 \mathrm{e}\left(\mathrm{L}^{*}=60.2\right.$, $\left.\mathrm{a}^{*}=33.1, \mathrm{~b}^{*}=15.3\right)$ showed dark orange solutions.

The data of the colorimetric measurement shows that increasing the amounts of the GSR samples will increase the redness value, $\mathrm{a}^{\star}$. For instance, $4 \mathrm{e}$ and $5 \mathrm{e}$ had the highest redness value $\mathrm{a}^{\star}$, while $4 \mathrm{a}$ and $5 \mathrm{a}$ had the lowest redness value, $a^{*}$. The GSR samples of F3 and F4 showed diffuse white or light colored solution due to the high value of luminosity, $\mathrm{L}^{*}$.

Even though the analysis used the same amount (mg) of GSR to react with the RGT reagent, the observation through the human eyes showed that the color changes of RGT towards $\mathrm{NO}_{2}^{-}$were different between firearms. The difference is because the GSR particles consist of partially burnt and unburnt chemical composition, in which the main composition is nitrocellulose. During the shooting process, the nitrocellulose had undergone degradation to form $\mathrm{NO}_{2}{ }^{-}$. In other words, the GSR from F4 contained higher amounts of $\mathrm{NO}_{2}{ }^{-}$in compared to the GSR from F3.

In addition, $10 \mathrm{mg}$ of GSR sample is the minimum amount that can differentiate the color of the reaction solution from the blank solution. Therefore, this amount should be the benchmark value in observing the effectiveness of the RGT reagent. Consequently, the RGT reagent successfully determined the nitrite compound in the GSR particles. The substitution of alpha-naphthol in the previous MGT reagent with 3-aminophenol will eliminate the need to use heat and the addition of acetic acid. Therefore, the invention of the RGT reagent can increase the efficiency of GSR screening tests at crime scenes by providing a portable and easy to use reagent.

\section{- CONCLUSION}

Using the RGT reagent to detect GSR on a shooter's hand and clothes will lead the investigators towards a better option to perform screening tests at crime scenes. The RGT analysis gave a slightly similar result to MGT. Although color intensity is not the main point for $\mathrm{NO}_{2}^{-}$ determination, there is an observable difference in color intensity between MGT and RGT. The effectiveness of the RGT chemical reagents will avoid the use of heat and acetic acid to facilitate the chromophoric reaction. Therefore, substituting the MGT with the RGT reagent as a screening method in detecting $\mathrm{NO}_{2}^{-}$as the main component in GSR will become a new alternative in forensic chemistry analysis. However, this method depends on the availability of the samples collected at the time an incident occurs.

\section{- ACKNOWLEDGMENTS}

The authors gratefully acknowledge and express gratitude to the Royal Malaysian Police for permitting the use of their facilities in the Ballistic Department, Forensic Laboratory Cheras, Malaysia. The authors also wish to thank CP Dato' Narenasegaran AL Thangaveloo, Supt Tan Yan Thian, and ASP Nik Norhisham Nik Ismail for a fruitful discussion and precious advice. Furthermore, the authors thank UiTM for the financial support through the Journal Support Fund. Lastly, the authors would also like to thank the Institute of Research Management and Innovation (IRMI), UiTM, for funding the study under BESTARI PERDANA Grant No: 600-IRMI/PERDANA 5/3 BESTARI (057/2018).

\section{- AUTHOR CONTRIBUTIONS}

SNJ analyzed and interpreted the shooting data and wrote the manuscript. ZNZ supervised SNJ's research work. MSMS prepared the shooting materials and performed the shooting test. MFS, MAAR, and MIAH mooted the idea, designed, and co-supervised SNJ's work. All authors read and approved the final manuscript.

\section{- REFERENCES}

[1] Vanini, G., Souza, M.O., Carneiro, M.T.W.D., Filgueiras, P.R., Bruns, R.E., and Romão, W., 2015, Multivariate optimisation of ICPOES instrumental parameters for $\mathrm{Pb} / \mathrm{Ba} / \mathrm{Sb}$ measurement in gunshot residues, Microchem. J., 120, 58-63. 
[2] Gassner, A.L., Ribeiro, C., Kobylinska, J., Zeichner, A., and Weyermann, C., 2016, Organic gunshot residues: Observations about sampling and transfer mechanisms, Forensic Sci. Int., 266, 369-378.

[3] Maitre, M., Kirkbride, K.P., Horder, M., Roux, C., and Beavis, A., 2017, Current perspectives in the interpretation of gunshot residues in forensic science: A review, Forensic Sci. Int., 270, 1-11.

[4] Vander Pyl, C., Ovide, O., Ho, M., Yuksel, B., and Trejos, T., 2019, Spectrochemical mapping using laser-induced breakdown spectroscopy as a more objective approach to shooting distance determination, Spectrochim. Acta, Part B, 152, 93-101.

[5] Tarifa, A., and Almirall, J.R., 2015, Fast detection and characterization of organic and inorganic gunshot residues on the hands of suspects by CMV-GC-MS and LIBS, Sci. Justice, 55 (3), 168-175.

[6] Bueno, J., and Lednev, I.K., 2014, Attenuated total reflectance-FTIR imaging for rapid automated detection of gunshot residue, Anal. Chem., 86 (7), 3389-3396.

[7] Doty, K.C., Muro, C.K., Bueno, J., Halámková, L., and Lednev, I.K., 2016, What can Raman spectroscopy do for criminalistics?, J. Raman Spectrosc., 47 (1), 39-50.

[8] Bueno, J., Sikirzhytski, V., and Lednev, I.K., 2013, Attenuated total reflectance-FT-IR spectroscopy for gunshot residue analysis: potential for ammunition determination, Anal. Chem., 85 (15), 7287-7294.

[9] López-López, M., Alvarez-Llamas, C., Pisonero, J., García-Ruiz, C., and Bordel, N., 2017, An exploratory study of the potential of LIBS for visualizing gunshot residue patterns, Forensic Sci. Int., 273, 124-131.

[10] Berger, J., Upton, C., and Springer, E., 2019, Evaluation of total nitrite pattern visualization as an improved method for gunshot residue detection and its application to casework samples, J. Forensic Sci., 64 (1), 218-222.

[11] Heines, S.V., 1958, Peter Griess-Discoverer of diazo compounds, J. Chem. Educ., 35 (4), 187.

[12] Dalby, O., Butler, D., and Birkett, J.W., 2010, Analysis of gunshot residue and associated materials - A review, J. Forensic Sci., 55 (4), 924-943.
[13] Costa, R.A., Motta, L.C., Destefani, C.A., Rodrigues, R.R.T., do Espirito Santo, K.S., Aquije, G.M.F.V., Boldrini, R., Athayde, G.P.B., Carneiro, M.T.W.D., and Romão, W., 2016, Gunshot residues (GSR) analysis of clean range ammunition using SEM/EDX, colorimetric test and ICP-MS: A comparative approach between the analytical techniques, Microchem. J., 129, 339-347.

[14] Chabaud, K.R., Thomas, J.L., Torres, M.N., Oliveira, S., and McCord, B.R., 2018, Simultaneous colorimetric detection of metallic salts contained in low explosives residue using a microfluidic paperbased analytical device ( $\mu$ PAD), Forensic Chem., 9, 35-41.

[15] Bailey, J.A., Casanova, R.S., and Bufkin, K., 2006, A method for enhancing gunshot residue patterns on dark and multicolored fabrics compared with the modified Griess test, J. Forensic Sci., 51 (4), 812814.

[16] Kersh, K.L., Childers, J.M., Justice, D., and Karim, G., 2014, Detection of gunshot residue on darkcolored clothing prior to chemical analysis, $J$. Forensic Sci., 59 (3), 754-762.

[17] Rosli, N.A., Osman, R., Saim, N., and Jaafar, M.Z., 2015, Application of chemometric techniques to colorimetric data in classifying automobile paint, Malays. J. Anal. Sci., 19 (4), 790-798.

[18] Neuhauser, S., and Handler, J., 2013, Color analysis of the equine endometrium: Comparison of spectrophotometry and computer-assisted analysis of photographs within the $L^{*} a^{*} b^{*}$ color space system, Vet. J., 197 (3), 753-760.

[19] Was-Gubala, J., and Starczak, R., 2015, UV-Vis microspectrophotometry as a method of differentiation between cotton fibre evidence colored with reactive dyes, Spectrochim. Acta, Part A, 142, 118-125.

[20] Caswell, L.R., 2013, "Reflectance Spectroscopy of Colored Overprints" in Proceedings of the First International Symposium on Analytical Methods in Philately, Eds. Lera, T.M., Barwis, J.H., and Herendeen, D.L., 101-107. 
[21] Aambø, M., 2011, Use of the "Video Spectral Comparator $6000 "$ as a non-destructive method for pigment identification-An experiment, Undergraduate Thesis, Gothenburg Uni., Sweeden.

[22] Goudsmits, E., Sharples, G.P., and Birkett, J.W., 2015, Recent trends in organic gunshot residue analysis, TrAC, Trends Anal. Chem., 74, 46-57.

[23] Haag, L.C., 2006, Shooting Incident Reconstruction, $3^{\text {rd }}$ Ed., Academic Press, London, UK.

[24] Haiyan, Y., Romain, S., Anne, S., Patrick, C., and Pierre, L., 2018, Comparison between two derivatization methods of nitrite ion labeled with 15 $\mathrm{N}$ applied to liquid chromatography-tandem mass spectrometry, Anal. Methods, 10 (31), 3830-3836.

[25] Waring, R.H., Hunter, J.O., Turner, C., Batty, C., and Ramzan, P.H.L, 2019, Nitrate supplementation in thoroughbred racehorses: Addition of beetroot juice to the equine diet and effects on the gut metabolome, Integr. Food Nutr. Metab., 6 (2), 1000246.

[26] Shrivastava, A., and Gupta, V.B., 2011, Methods for determination of limit of detection and limit of quantification of the analytical methods, Chron. Young Sci., 2 (1), 21-25.

[27] Samal, L., and Prusty, A., 2019, Development and validation of UV-Visible spectrometric method for determination of duloxetine, Int. J. Pharm. Pharm. Sci., 11 (3), 27-31.

[28] Lappas, N.T., and Lappas, C.M., 2016, Forensic Toxicology: Principles and Concepts, $1^{\text {st }}$ Ed., Academic Press, London, UK.

[29] Guimarães, V., Durão, H., and Azenha, M., 2014, Detailed validation of a method for the determination of nitrate in water by UV/Vis spectroscopy, J. AOAC Int., 2014, 12-007. 